\title{
Association of serum ferritin with insulin resistance in women with polycystic ovarian syndrome
}

\author{
Taslima Begum $^{1 *}$, Shakeela Ishra², Begum Shaira Sharifa ${ }^{3}$, Shamsun Nahar ${ }^{4}$, \\ Hosne Ara Begum ${ }^{1}$, Sadia Sultana Khan ${ }^{5}$, Mahbuba Khanum ${ }^{6}$
}

\author{
${ }^{1}$ Department of Obstretics and Gynecology, Chittagong Medical College Hospital, Chittagong, Bangladesh \\ ${ }^{2}$ Department of Reproductive Endocrinology and Infertility, Bangabandhu Sheikh Mujib Medical University, \\ Bangladesh \\ ${ }^{3}$ Department of Obstretics and Gynecology, NICRH, Mohakhali, Dhaka, Bangladesh \\ ${ }^{4}$ Department of Obstretics and Gynecology, 250 Beded Hospital, Magura, Bangladesh \\ ${ }^{5}$ Gastro Medicine, Sheikh Russel Gastro Liver Institute and Hospital, Mohakhali, Dhaka, Bangladesh \\ ${ }^{6}$ Department of Obstretics and Gynecology, Dhaka Medical College, Dhaka, Bangladesh
}

Received: 01 March 2021

Accepted: 12 July 2021

*Correspondence:

Dr. Taslima Begum,

E-mail: taslima.dr@gmail.com

Copyright: () the author(s), publisher and licensee Medip Academy. This is an open-access article distributed under the terms of the Creative Commons Attribution Non-Commercial License, which permits unrestricted non-commercial use, distribution, and reproduction in any medium, provided the original work is properly cited.

\begin{abstract}
Background: Emerging scientific evidence has disclosed unsuspected influences between iron metabolism, insulin resistance and type 2 diabetes. Even mildly elevated body iron stores are associated with statistically significant increases in glucose homeostasis indices. But till now high serum ferritin associated with type 2 diabetes is not recognized as an entity in the current clinical guidelines for the management of type 2 diabetes.

Methods: This was a Cross sectional study carried out from September 2016 to March, 2017 at PCO clinic of infertility outpatient department (OPD), department of obstetrics and gynecology, Bangabandhu Sheikh Mujib Medical University, Dhaka, Bangladesh. The study population consisted of all the diagnosed PCOS patients. Purposive sampling Main outcome variable: serum ferritin level and insulin resistance index (Homeostatic model assessment of insulin resistance: HOMA-IR).

Results: Most of the (90.9\%) patients were aged 20-30 years having BMI $>25 \mathrm{~kg} / \mathrm{m}^{2}$, mostly overweight $(52.53 \%)$ or obese $(25.25 \%)$. Significant increase of serum ferritin level $(72.89 \pm 34.97$; $=0.001)$ was noted in PCOS patients with insulin resistance. Marked increase in serum ferritin $(82.81 \pm 31.57, \mathrm{p}<0.001)$, fasting serum insulin $(16.39 \pm 7.1$; $\mathrm{p}<0.001)$, HOMA-IR $(3.51 \pm 1.55 ; \mathrm{p}<0.001)$ and more cases with insulin resistance $(78.3 \% ; \mathrm{p}<0.001)$ were found in women with high ferritin level (when $\geq 45.5 \mathrm{ng} / \mathrm{ml}$ ). Statistically significant strong positive correlation between serum ferritin level and fasting insulin level $(\mathrm{r}=0.528 ; \mathrm{p}<0.001)$ as well as HOMA-IR $(\mathrm{r}=0.492 ; \mathrm{p}<0.001)$ were observed.

Conclusions: These results demonstrated that elevated level of serum ferritin was associated with insulin resistance in PCOS women.
\end{abstract}

Keywords: Serum ferritin, Insulin resistance, Polycystic ovarian syndrome

\section{INTRODUCTION}

Polycystic ovary syndrome (PCOS) is a complex and heterogeneous disorder characterized by hyperandrogenemia, hyperinsulinemia, insulin resistance, and chronic anovulation. It is the most common endocrine disorder in women of reproductive age. It is now well- known that PCOS is associated with insulin resistance and abnormal glucose tolerance and later on type 2 diabetes. Serum ferritin levels are also increased in PCOS patients, suggesting mild iron overload. ${ }^{1-3}$

Factors contributing to potential iron overload in women with PCOS include the iron-sparing effect of chronic 
anovulation and oligo or amenorrhea, insulin resistance, and a decrease in hepcidin, which leads to increased iron absorption. ${ }^{2,3}$ Iron is essential for cell metabolism and is a constituent of hemoproteins, such as hemoglobin, myoglobin, and cytochrome $\mathrm{P} 450$, and total body iron levels are precisely regulated under normal physiologic conditions. ${ }^{4}$ Ferritin is a ubiquitous intracellular protein that stores iron in cells and its circulating levels serve as a marker for body iron stores. ${ }^{2}$ Ferritin is essential for the regulation of iron homeostasis, it is found in proportion to the size of cellular iron stores in absence of other confounding factors. $^{2}$ Iron is a strong pro-oxidant, and high body iron levels are associated with an increased level of oxidative stress, which causing inhibition of insulin internalization and actions, results in hyperinsulinemia and insulin resistance. ${ }^{5,6}$ In the progression of diabetes excess iron induced free radicals can cause both $\beta$ cell failure and insulin resistance. ${ }^{6,7}$ The first and clearest evidence for a relation between iron and human diabetes was observed in individuals with pathologic iron overload like hereditary hemochromatosis $(\mathrm{HH})$, and later on also with transfusional iron overload. ${ }^{6,7}$ Another study by Jiang et al in 2004 showed higher iron stores reflected by an elevated ferritin concentration are associated with an increased risk of type 2 diabetes in apparently healthy women without known diabetes risk factors. ${ }^{6}$ In one study phlebotomy was followed by decreases in serum glucose, cholesterol, triglycerides and apoprotein $\mathrm{B}$, and by improvement in both $\beta$-cell secretion and peripheral insulin action in patients with type 2 diabetes. ${ }^{5,7} \mathrm{~A}$ recent pilot study done by Wilson MS and Thompson EW in year 2016 concluded that in patients with type 2 diabetes and also with elevated serum ferritin, venesection can be used successfully with oral pharmacotherapy, thereby avoiding the use of insulin. ${ }^{8}$ In 1997, a cross-sectional population study showed that mildly elevated serum ferritin was associated with elevated fasting serum insulin, that means persons with the higher serum ferritin needed to produce more insulin to remain normoglycemic. ${ }^{9} \mathrm{~A}$ meta-analysis has showed that elevated levels of serum ferritin may help to identify individuals at risk of type 2 diabetes and in 2008, Le and co-workers suggested that serum ferritin concentration could be used as a predictor for diabetes. ${ }^{10}$

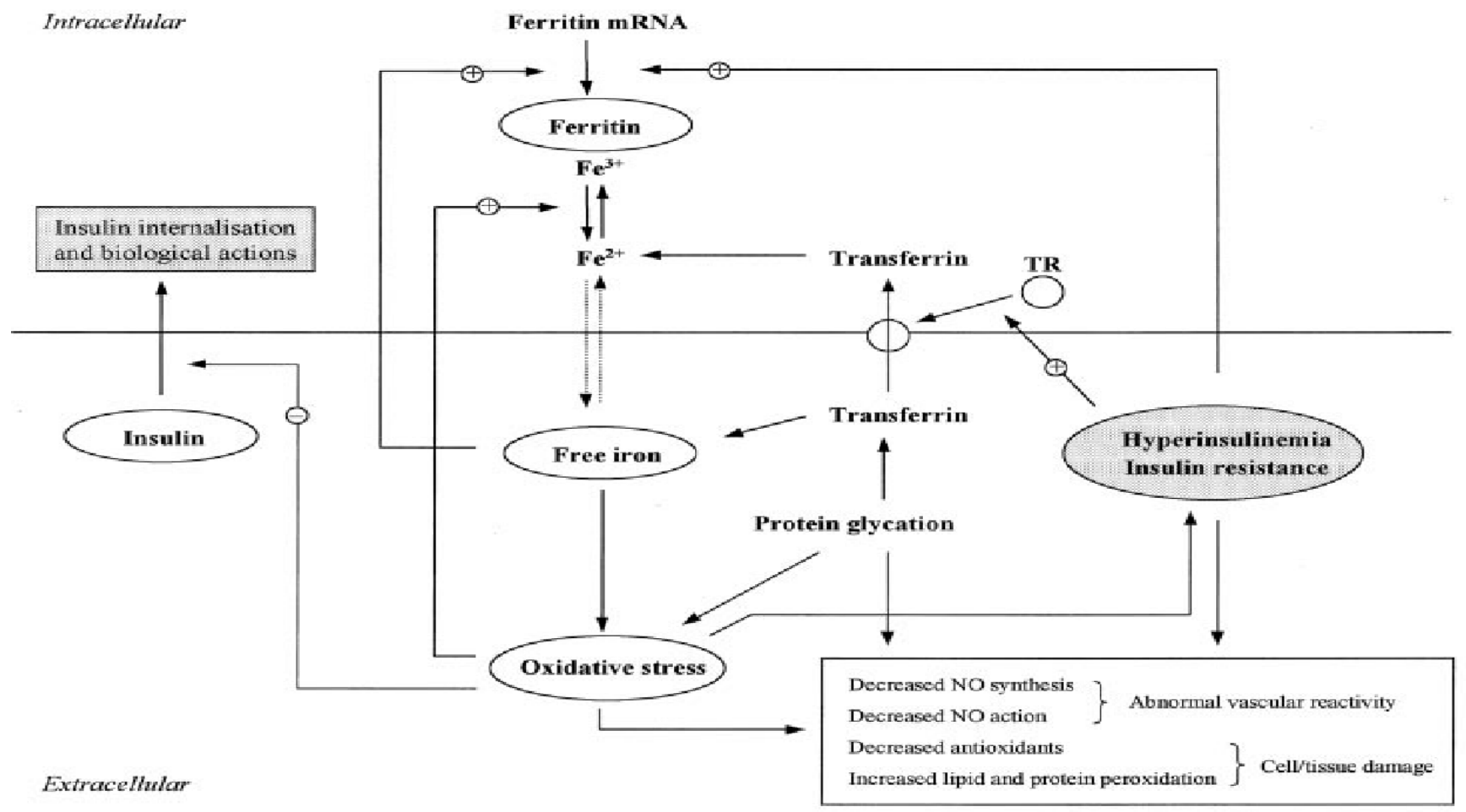

Figure 1: Summary of iron interactions with insulin sensitivity.

Even mildly elevated body iron stores are associated with statistically significant increases in glucose homeostasis indices. ${ }^{3}$ But till now high serum ferritin associated with type 2 diabetes is not recognized as an entity in the current clinical guidelines for the management of type 2 diabetes. The present study was thus designed to determine the hormone fasting insulin levels, fasting blood sugar levels and serum ferritin levels by standard methods and then to assess whether there is any association of insulin resistance and serum ferritin in PCOS patients.

\section{Objectives}

The objective of this study was to see the association of serum ferritin level with insulin resistance in PCOS women and to estimate serum ferritin level in PCOS patients.

\section{METHODS}

This cross-sectional analytical study was conducted in BSMMU, during September 2016 to March 2017. The 
study population consisted of all the diagnosed PCOS patients of reproductive age attending PCOS clinic of infertility OPD of the department of Obstetrics and Gynecology at Bangabandhu Sheikh Mujib Medical University, during study period fulfilling the inclusion and exclusion criteria. Statistical analyses of the results were obtained by using window-based computer software devised with Statistical Packages for Social Sciences (SPSS-26). The results were presented in tables, figures, diagrams. Comparison of means made by using Student ttest and categorical data was analyze by Chi square test, Odds ratio (OR) with $95 \%$ confidence interval and $\mathrm{p}$ value $<0.05$ was considered significant.

\section{Inclusion criteria}

Inclusion criteria were all the patients attend PCOS clinic of infertility OPD with following criteria age 20-40 years and diagnosed as PCOS according to the 2003 Rotterdam revised consensus meeting.

\section{Exclusion criteria}

Exclusion criteria were recent $\mathrm{H} / \mathrm{O}$ blood transfusion or intake of iron, history of heavy menstrual bleeding, overt diabetes, known chronic inflammatory conditions e.g.; chronic cough, asthma, tuberculosis and anemia: hemoglobin $<11 \mathrm{~g} / \mathrm{dl}$ was excluded, which is frequently associated with iron deficiency.

\section{RESULTS}

A population total of 99 previously diagnosed infertile PCOS patients were included in this study maintaining selection criteria. The patients with PCOS attending the study place were interviewed, thoroughly examined by complete history and physical examination. Routine laboratory screening e.g. complete blood count (CBC), TVS, OGTT, thyroid-stimulating hormone (TSH), serum prolactin, D2 FSH, D2 LH and testosterone was done. Then serum ferritin level and insulin resistance were assessed of all subjects after an overnight fast of 8-12 h. regarding demographic variables of the patients, it was observed that most of the $(90.9 \%)$ patients belongs to age 20-30 years. The mean age was found $25.49 \pm 3.81$ years with range from 20 to 37 years. Age distribution of study population is illustrated in Figure 1. Mean duration of infertility was found $4.33 \pm 3.2$ years and most $(74.75 \%)$ of them were suffering from primary infertility. Majority (>98\%) patients had duration of menstrual cycle of more than 6 weeks and mean cycle length was found 13.06 \pm 8.02 weeks. Mean modified Ferriman Gallway score of study population was $7.73 \pm 3.82$ and hirsutism in term of modified Ferriman Gallway score $\geq 6$ was noted in $32.32 \%$ cases. HOMA-IR index was $2.73 \pm 6.59$. Insulin resistance was noted in $(46.46 \%)$ cases. On the other hand, mean serum ferritin level was found $54.38 \pm 35.62 \mathrm{ng} / \mathrm{ml}$ and high ferritin was noted in $47.47 \%$ cases. Endocrine evaluation of the patients showed that mean serum FSH was $5.78 \pm 2.02 \mathrm{mU} / \mathrm{ml}$, mean $\mathrm{LH}$ was $8.27 \pm 5.47 \mathrm{mU} / \mathrm{ml}$. Mean total serum testostosterone was $2.43 \pm 1.17 \mathrm{nmol} / 1$. Normal androgen level was noted in majority $(56.57 \%)$ cases. Where significantly high level of serum LH $(\mathrm{p}=0.022)$ and more cases with metabolic syndrome $(p=0.041)$ were noted in low ferritin group. Table 4 Illustrates the correlation between serum ferritin levels and related parameters in PCOS women. A statistically significant strong positive correlation between serum ferritin level and fasting insulin level $(\mathrm{r}=0.528 ; \mathrm{p}<0.001)$ as well as HOMA-IR $(r=0.492 ; \mathrm{p}<0.001)$ were observed. Serum ferritin were positive weakly correlated with total testosterone, triglyceride, BMI, and mFG score and negative weakly correlated with HDL, metabolic syndrome among study.

Table 1: Hormonal and biochemical characteristic of study population.

\begin{tabular}{|c|c|}
\hline Variables & Mean \pm SD or percentage \\
\hline Hemoglobin level (g/dl) & $12.84 \pm 0.97$ \\
\hline Fasting blood sugar (mmol/l) & $4.82 \pm 0.63$ \\
\hline Fasting insulin $(\mathrm{mU} / \mathrm{ml})$ & $13.74 \pm 6.59$ \\
\hline IR index (HOMA method) & $2.73 \pm 1.44$ \\
\hline Median HOMA-IR & 2.64 \\
\hline \multicolumn{2}{|l|}{ Insulin resistance present } \\
\hline IR $\geq 2.7(\%)$ & 46.46 \\
\hline Insulin resistance absent $(\%)$ & 53.54 \\
\hline Serum ferritin level (ng/ml) & $54.38 \pm 35.62$ \\
\hline Median (ng /ml) & 44.8 \\
\hline High ferritin (ferritin $\geq 45.5 \mathrm{ng} / \mathrm{ml}$ ) & 47.47 \\
\hline Low ferritin (\%) & 52.53 \\
\hline FSH (mU/ml) & $5.78 \pm 2.02$ \\
\hline LH (mU/ml) & $8.27 \pm 5.47$ \\
\hline Total testosterone (nmol/l) & $2.43 \pm 1.17$ \\
\hline Normal androgen level (\%) & 56.57 \\
\hline Hyperandrogenism ( $\mathrm{T}$ testosterone $\geq 2.32 \mathrm{nmol} / \mathrm{l}$ ) & 43.43 \\
\hline Total cholesterol (mg/dl) & $193.40 \pm 34.6$ \\
\hline
\end{tabular}


Variables

LDL (mg/dl)

HDL (mg/dl)

TG (mg/dl)

Metabolic syndrome present $(\%)$

Metabolic syndrome absent (\%)
Mean \pm SD or percentage

$125.13 \pm 31.12$

$39.41 \pm 8.96$

$148.30 \pm 75.80$

59.60

40.40

Table 2: A comparison of clinical characteristics of PCOS women between high and low ferritin groups.

\begin{tabular}{|c|c|c|c|}
\hline Clinical parameters & High ferritin ( $\mathrm{N}=47)$ & Low ferritin ( $\mathbf{N}=\mathbf{5 2})$ & P value \\
\hline Age (years) & $25.66 \pm 3.94$ & $25.35 \pm 3.72$ & 0.685 \\
\hline Menstrual cycle length (weeks) & $14.11 \pm 10.08$ & $12.12 \pm 5.5$ & 0.22 \\
\hline BMI $\left(\mathrm{kg} / \mathrm{m}^{2}\right)$ & $28.60 \pm 3.24$ & $27.07 \pm 3.67$ & $0.03^{\mathrm{a}}$ \\
\hline mFG score & $8.31 \pm 3.86$ & $7.21 \pm 3.7$ & 0.151 \\
\hline Waist to hip ratio & $0.92 \pm .041$ & $0.92 \pm 0.44$ & 0.991 \\
\hline Cases with central obesity (\%) & 46.9 & 53.1 & 0.499 \\
\hline Cases with Acanthosis nigricans (\%) & 46.7 & 53.3 & 0.883 \\
\hline Subjects with hirsutism (\%) & 52.2 & 47.8 & 0.170 \\
\hline Systolic pressure (mmHg) & $123.40 \pm 14.29$ & $123.07 \pm 11.42$ & 0.900 \\
\hline Diastolic pressure (mmHg) & $80.08 \pm 8.80$ & $80.38 \pm 8.56$ & 0.864 \\
\hline
\end{tabular}

Note: Data are either mean \pm SD or percentage, statistical significance ${ }^{a}$ when $p<0.05$ insulin resistance means: HOMA-IR $\geq 2.7$.

Table 3: A comparison of biochemical and metabolic characteristics of PCOS women between high and low ferritin groups.

\begin{tabular}{|c|c|c|c|}
\hline Laboratory parameters & High ferritin $(\mathrm{N}=47)$ & Low ferritin ( $\mathrm{N}=52)$ & P value \\
\hline Serum ferritin in $\mathrm{ng} / \mathrm{ml}$ & $82.81 \pm 31.57$ & $28.68 \pm 10.99$ & $<0.001^{\mathrm{a}}$ \\
\hline Hemoglobin in g/dl & $13.10 \pm 0.97$ & $12.59 \pm 0.92$ & $0.009^{a}$ \\
\hline Metabolic syndrome present (\%) & 44.1 & 55.9 & $0.041^{\mathrm{a}}$ \\
\hline HDL in $\mathrm{mg} / \mathrm{dl}$ & $38.27 \pm 8.22$ & $40.44 \pm 9,54$ & 0.232 \\
\hline Triglycerides in $\mathrm{mg} / \mathrm{dl}$ & $164.78 \pm 88.22$ & $133.40 \pm 59.55$ & $0.043^{\mathrm{a}}$ \\
\hline LDL in $\mathrm{mg} / \mathrm{dl}$ & $129.01 \pm 31.16$ & $121.62 \pm 30.52$ & 0.241 \\
\hline Total cholesterol in $\mathrm{mg} / \mathrm{dl}$ & $199.31 \pm 36.69$ & $188.05 \pm 32.76$ & 0.110 \\
\hline Total testosterone (ng/ml) & $2.62 \pm 1.26$ & $2.26 \pm 1.05$ & 0.130 \\
\hline With hyperandrogenism (\%) & 53.5 & 46.5 & 0.294 \\
\hline Fasting insulin (uIU/ml) & $16.39 \pm 7.1$ & $9.44 \pm 3.79$ & $<0.001^{\mathrm{a}}$ \\
\hline Fasting glucose (mmol/l) & $4.81 \pm 0.69$ & $4.83 \pm 0.59$ & 0.85 \\
\hline HOMA-IR & $3.51 \pm 1.55$ & $2.03 \pm 0.86$ & $<0.001^{\mathrm{a}}$ \\
\hline With Insulin resistance (\%) & 78.3 & 21.7 & $<0.001^{\mathrm{a}}$ \\
\hline LH (mIU/ml) & $6.98 \pm 4.1$ & $9.45 \pm 6.2$ & $0.022^{\mathrm{a}}$ \\
\hline FSH (mIU/ml) & $5.86 \pm 2.25$ & $5.69 \pm 1.80$ & 0.68 \\
\hline
\end{tabular}

Note: Data are either mean \pm SD or are percentage, statistical significance a when $\mathrm{p}<0.05$. Low ferritin=serum ferritin level $<45.5 \mathrm{ng} / \mathrm{ml}$; high ferritin=serum ferritin level $\geq 45.5 \mathrm{ng} / \mathrm{ml}$; HOMA-IR=homeostasis model assessment insulin resistance index; HDL=high-density lipoprotein; LDL=low-density lipoprotein.

Table 4: Correlation of serum ferritin with clinical, hormonal, biochemical and metabolic components of PCOS patients $(\mathrm{N}=99)$.

\begin{tabular}{|c|c|c|}
\hline Parameters correlated with ferritin & Pearson correlation $(\mathbf{r})$ & P value \\
\hline Menstrual cycle length & 0.044 & 0.665 \\
\hline Total testosterone & 0.136 & 0.179 \\
\hline Fasting insulin & 0.528 & $<0.001^{\mathrm{a}}$ \\
\hline Fasting blood sugar & -0.079 & 0.437 \\
\hline HOMA-IR & 0.492 & $<0.001^{\mathrm{a}}$ \\
\hline Cholesterol & -0.049 & 0.629 \\
\hline Triglyceride & 0.107 & 0.291 \\
\hline HDL & -0.131 & 0.196 \\
\hline LDL & -0.065 & 0.522 \\
\hline SBP & 0.021 & 0.835 \\
\hline
\end{tabular}




\begin{tabular}{|lll|}
\hline Parameters correlated with ferritin & Pearson correlation $(\mathbf{r})$ & P value \\
\hline DBP & -0.025 & 0.806 \\
\hline BMI & 0.174 & 0.085 \\
\hline mFG score & 0.193 & 0.056 \\
\hline Waist hip ratio & 0.06 & 0.500 \\
\hline Metabolic syndrome & -0.1189 & 0.246 \\
\hline
\end{tabular}

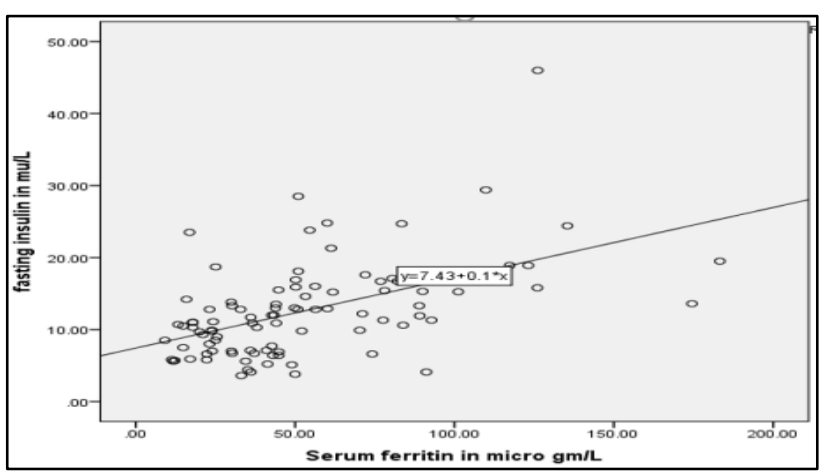

Figure 2: Scatter plot showing linear correlation between serum ferritin and fasting insulin level.

\section{DISCUSSION}

This study aimed to determine the association between serum ferritin level and insulin resistance in women with PCOS. In the present study serum ferritin level is found to be associated with insulin resistance in women with PCOS. Previous findings suggest there is a relationship between iron overload and the development of insulin resistance. The central role of iron in biology can be understood by the fact that iron is the fourth most abundant element in Earth's crust as well as the transition element, most abundant in all living organisms including human being. ${ }^{5}$ Iron induced cell oxidative stress can explain some extent of its association with abnormal insulin sensitivity. ${ }^{5}$

On the other hand, it is well established that there is increased NIDDM among women with PCOS that has been ascribed to the insulin resistance characteristic of PCOS. ${ }^{11,17,22,33}$ Serum ferritin levels are also found to be increased in PCOS, suggesting mild iron overload., 1,2,26 Therefore there is a possibility that increased iron status of PCOS patients is an associated feature with insulin resistance syndrome. A total of 99 previously diagnosed PCOS patients were included in this study maintaining selection criteria. Patients aged 20-40 years diagnosed as PCOS according to the 2003 Rotterdam revised consensus meeting were included. ${ }^{31}$ PCOS patients with known hormonal disorder or medical disorder, with recent $\mathrm{H} / \mathrm{O}$ blood transfusion or intake of iron, anemic $(\mathrm{Hb}<11 \mathrm{~g} / \mathrm{dl})$, with history of heavy menstrual bleeding and history of taking drugs in previous 6 months like OCP, glucocorticoids, thiazide diuretics, anti-androgens, antidiabetic drugs, anti-obesity drugs or other hormonal drugs were excluded from the study.

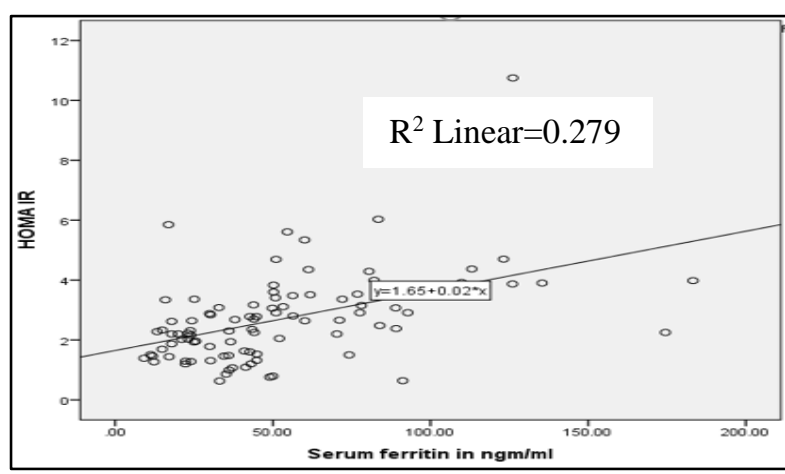

Figure 3: Scatter plot showing linear correlation between serum ferritin and HOMA-IR.

In the present study, it was observed that most of the (90.9\%) patients were aged $20-30$ years. The mean age was found $25.49 \pm 3.81$ years. In another study Lauritsen et al reported majority $(69.0 \%)$ of the women of polycystic ovaries were under the age of 30 years, which is consistent with present study. ${ }^{14}$ Menstrual dysfunction with cycle duration $>6$ weeks was observed in majority ( $>98 \%$ ) of PCOS patients; mean menstrual cycle length was $13.06 \pm 8.02$ weeks. Rahila et al reported $71 \%$ patients had oligomenorrhea in their study. ${ }^{31}$ They stated that oligomenorrhea was most common symptom in unmarried study group and second common complaint in married group. ${ }^{31}$ Mean modified Ferriman Gallway (mFG) score of study population was $7.73 \pm 3.82$ and hirsutism in term of $\mathrm{mFG}$ score $\geq 6$ was noted in $32.32 \%$ cases. In a study, it was reported that $31 \%$ patients were hirsute. and the result of their study is almost similar to present study. A review article by Dumitrescu et.al. described that hirsutism is likely to be present approximately $60 \%$ of women with PCOS. $^{24}$

In the present study, total serum testostosterone was $2.43 \pm 1.17 \mathrm{nmol} / 1$ and hyperandrogenism was noted in $43.43 \%$ cases; and normal androgen level was noted in majority $(56.57 \%)$ of the cases. In a study, total testosterone level was reported to be elevated in $60 \%$ of patients. ${ }^{31}$ In another study elevated circulating androgen (including free testosterone) levels were observed in 80$90 \%$ of PCOS women with oligomenorrhea. ${ }^{25}$ In the present study serum ferritin were found positive weakly correlated with total testosterone. Finding of present study regarding presence hyperandrogenism was not consistent with previous findings. This is may be due to the fact that in this study place measurement of free testosterone is not available till date and assays for total testosterone lack 
precision and sensitivity in the female testosterone range, including testosterone levels typical of PCOS. ${ }^{24}$

In this study mean fasting blood sugar and fasting insulin level was $4.82 \pm 0.63 \mathrm{mmol} / \mathrm{l}$ and $13.74 \pm 6.59 \mathrm{mU} / \mathrm{ml}$ respectively and HOMA-IR index was $2.73 \pm 6.59$. Previous literature review showed that approximately $50 \%$ to $70 \%$ of women with PCOS had some degree of insulin resistance. ${ }^{21}$ In present study insulin resistance was noted only in $46.46 \%$ cases. Prevalence of insulin resistance of this study was a bit lower than prevalence stated in previous studies. This lower prevalence of insulin resistance may be due to our study population was belonging to mean weight range of overweight $(52.53 \%)$ instead obese $(25.25 \%)$ and this study was non-BMI matched study. High ferritin $(\geq 45.5 \mathrm{ng} / \mathrm{ml})$ was noted in $47.47 \%$ cases. This finding is consistent with literature reviews, that PCOS showed increased ferritin concentrations compared to controls.

Some study found Serum ferritin levels were increased in women with PCOS. ${ }^{35}$ Statistically significant increase of Serum ferritin level $(72.89 \pm 34.97$ vs $38.31 \pm 27.69$; $\mathrm{p}=0.001$ ) was noted in PCOS patients with insulin resistance in comparison without insulin resistance. Further grouping of the study populations was done by serum ferritin level $\geq 45.5 \mathrm{ng} / \mathrm{ml}$ as high ferritin and other low ferritin group. Further grouping demonstrated significantly higher level of hemoglobin $(\mathrm{p}=0.009)$, marked increase in serum ferritin $(82.81 \pm 31.57$ vs $28.68 \pm 10.99 ; \mathrm{p}<0.001)$, fasting serum insulin $(16.39 \pm 7.1$ vs $9.44 \pm 3.79 ; \mathrm{p}<0.001)$ and HOMA-IR $(3.51 \pm 1.55$ vs $2.03 \pm 0.86 ; \mathrm{p}<0.001)$ were found in high ferritin group in comparison with low ferritin group. Cases with insulin resistance were significantly more $(78.3 \%$ vs $21.7 \%$; $\mathrm{p}<0.001$ ) in high ferritin group in comparison with low ferritin group. Statistically significant strong positive correlation between serum ferritin level and fasting insulin level (Figure 4) $(\mathrm{r}=0.528 ; \mathrm{p}<0.001)$ as well as HOMA-IR $(r=0.492 ; \mathrm{p}<0.001)$ were observed in the present study.

The present study showed the presence of metabolic syndrome in more than half $(59.60 \%)$ of the cases. Presence of cases of metabolic syndrome $(33.3 \%$ vs $26.3 \%$; $p=0.025$ ) were seen significantly higher in PCOS with insulin resistance than without insulin resistance. A systematic review and meta-analysis noticed that frequent diagnosis of the metabolic syndrome in PCOS is strongly associated with insulin resistance. ${ }^{18}$ This finding is consistent with findings of meta-analysis that women with PCOS had a greater prevalence of the metabolic syndrome than women without PCOS. ${ }^{18}$ This observation was supporting the common etiological role of insulin resistance in both PCOS and the metabolic syndrome. ${ }^{20}$ Serum ferritin were found negative weakly correlated with metabolic syndrome and surprisingly in low ferritin group more presence of metabolic syndrome $(p=0.041)$ were noted. This is may be due to the fact that grouping between low ferritin and high ferritin were not BMI matched. In literature review it was noted that iron also affects lipid metabolism, adipocyte biology, and obesity. ${ }^{7}$

The association of iron deficiency with obesity has been confirmed by previous findings that greater prevalence of iron deficiency in obese (39\%) and overweight (12\%) children and adolescents than normal weight children whose prevalence of iron deficiency is only $4 \% .^{7}$ In the present study, significantly high level of serum LH ( $p=0.022$ ) was noted in low ferritin group whereas high LH is said to be associated with insulin resistance. This variation of level of gonadotrophin is not uncommon, may be explained by characteristic derangements of gonadotropin pulsatile release in PCOS that can escape detection on random blood samples. The presence of significantly raised LH and more metabolic syndrome in low ferritin group may be interrelated and need further exploration.

\section{Limitations}

Like all other study the present study was also not without limitations. The limitations were as follows: The study population was selected from one selected tertiary hospital in Dhaka city, all the women were infertile PCOS. So that the results of the study may not reflect the exact picture of the whole PCOS population. The present study was conducted at a very short period of time. Small sample size was also a limitation of the present study. Therefore, in future further study may be under taken with large sample size. Because of the cross-sectional nature of the study, it cannot determine the causal relationship between serum ferritin and glucose metabolism.

\section{CONCLUSION}

PCOS women with infertility was studied regarding insulin resistance and serum ferritin level. Most of the PCOS patients were in $3^{\text {rd }}$ decade, either overweight or obese having central obesity. Significantly increased fasting insulin level, HOMA-IR, and insulin resistant cases were reported in PCOS patients with high ferritin level. Significantly increased serum ferritin was found in insulin resistance cases. Statistically significant strong positive correlation was observed between serum ferritin and fasting insulin as well as between serum ferritin and HOMA IR. These results demonstrated that elevated level of serum ferritin was associated with insulin resistance in PCOS women.

\section{Recommendations}

Further community based or multicenter studies can be undertaken by including large number of patients. Experimental and prospective studies are warranted to elucidate the role of serum ferritin in glucose metabolism. Therefore, the longitudinal relationship study between serum ferritin levels and glucose metabolism can be ascertained. 
Funding: No funding sources

Conflict of interest: None declared

Ethical approval: The study was approved by the Institutional Ethics Committee

\section{REFERENCES}

1. Morreale HF, Ramirez M, Blasco F, Carretero JI, Sancho J, Millan JL. Body iron stores are increased in overweight and obese women with polycystic ovary syndrome. Diabetes Care. 2005;28(8):2042-4.

2. Morreale HF. Iron metabolism and the polycystic ovary syndrome. Trends Endocrinol Metab. 2012;23(10):509-15.

3. Ko PC, Huang SY, Hsieh CH, Hsu MI, Hsu CS. Serum ferritin levels and polycystic ovary syndrome in obese and nonobese women. Taiwan J Obstet Gynecol. 2015;54(4):403-7.

4. Crownover BK, Covey CJ. Hereditary hemochromatosis. Am Fam Physician. 2013;87(3):183-90.

5. Real JM, Bermejo A, Ricart W. Cross-talk between iron metabolism and diabetes. Diabetes. 2002;51(8):2348-54.

6. Jiang R, Manson JE, Meigs JB, Ma J, Rifai N, Hu FB. Body iron stores in relation to risk of type 2 diabetes in apparently healthy women. JAMA. 2004;291(6):711-7.

7. Judith AS, Donald AM. Iron and Diabetes Risk. Cell metabolism. 2013;17(3):329-41.

8. Wilson MS, Thompson EW. Venesection is an effective non-pharmacological treatment for patients with high serum ferritin type 2 diabetes. J Clinical Translational Endocrinol Case Rep. 2017;3:1-5.

9. Tuomainen TP, Nyyssonen K, Salonen R, Tervahauta A, Korpela H, Lakka T, et al. Body iron stores are associated with serum insulin and blood glucose concentrations. Population study in 1,013 eastern Finnish men. Diabetes Care. 1997;20(3):426-8.

10. Le TD, Bae S, Ed HC, Singh KP, Blair SN, Shang N. Effects of Cardiorespiratory Fitness on Serum Ferritin Concentration and Incidence of Type 2 Diabetes: Evidence from the Aerobics Center Longitudinal Study (ACLS). Rev Diabet Stud. 2008;5(4):245-52.

11. Dunaif A. Insulin resistance and the polycystic ovary syndrome: mechanism and implications for pathogenesis. Endocr Rev. 1997;18(6):774-800.

12. March WA, Moore VM, Willson KJ, Phillips DI, Norman RJ, Davies MJ. The prevalence of polycystic ovary syndrome in a community sample assessed under contrasting diagnostic criteria. Hum Reprod. 2010;25(2):544-51.

13. Rotterdam ESHRE/ASRM-Sponsored PCOS consensus workshop group. Revised 2003 consensus on diagnostic criteria and long-term health risks related to polycystic ovary syndrome (PCOS). Hum Reprod. 2004;19(1):41-7.

14. Lauritsen MP, Bentzen JG, Pinborg A, Loft A, Forman JL, Thuesen LL, et al. The prevalence of polycystic ovary syndrome in a normal population according to the Rotterdam criteria versus revised criteria including anti-Mullerian hormone. Hum Reprod. 2014;29(4):791-801.

15. Unluturk U, Harmanci A, Kocaefe C, Yildiz BO. The Genetic Basis of the Polycystic Ovary Syndrome: A Literature Review Including Discussion of PPARgamma. PPAR Res. 2007;49109.

16. Tang T, Lord JM, Norman RJ, Yasmin E, Balen AH. Insulin-sensitising drugs (metformin, rosiglitazone, pioglitazone, D-chiro-inositol) for women with polycystic ovary syndrome, oligo amenorrhoea and subfertility. Cochrane Database Syst Rev. 2012;(5):3053.

17. Jakubowicz D, Wainstein J, Homburg R. The link between polycystic ovarian syndrome and type 2 diabetes: preventive and therapeutic approach in Israel. Isr Med Assoc J. 2012;14(7):442-7.

18. Moran LJ, Misso ML, Wild RA, Norman RJ. Impaired glucose tolerance, type 2 diabetes and metabolic syndrome in polycystic ovary syndrome: a systematic review and meta-analysis. Human Reproduction Update. 2010;16(4):347-63.

19. Lim SS, Davies M J, Norman R J, and Moran L J Overweight, obesity and central obesity in women with polycystic ovary syndrome: a systematic review and meta-analysis. Human Reproduction Update. 2012;18(6):618-37.

20. Speroff L, Fritz MA. Clinical gynecologic endocrinology and infertility. 8th ed. Philadelphia: Lippincott Williams \& Wilkins; 2011.

21. Lee H, Oh JY, Sung YA, Chung H. Is insulin resistance an intrinsic defect in asian polycystic ovary syndrome? Yonsei Med J. 2013;54(3):609-14.

22. Wang HS, Wang TH. Polycystic ovary syndrome (PCOS), insulin resistance and insulin-like growth factors (IGfs)/IGF-binding proteins (IGFBPs). Chang Gung Med J. 2003;26(8):540-53.

23. Kandarakis E, Dunaif A. Insulin resistance and the polycystic ovary syndrome revisited: an update on mechanisms and implications. Endocr Rev. 2012;33(6):981-1030.

24. Dumitrescu R, Mehedintu C, Briceag I, Purcarea VL, Hudita D. The polycystic ovary syndrome: an update on metabolic and hormonal mechanisms. J Med Life. 2015;8(2):142-5.

25. Sakumoto T, Tokunaga Y, Terada Y, Tanaka H, Nohara M, Nakaza A, et al. Implications of Insulin Resistance/Hyperinsulinemia on Reproductive Function in Infertile Women with Polycystic Ovary Syndrome. 2012.

26. Zamily HA. Iron Status and Lipid Profile in Irregular Cycle Women with Polycystic Ovary Syndrome. Int J Sci Res. 2015;4(10):1153-58.

27. Jehn M, Jeanne MC, Guallar E. Serum ferritin and risk of metabolic syndrome in U.S. adults. Diabetes Care. 2004;27:2422-28.

28. Emma A. Ferritin (serum, plasma). Association for Clinical Biochem. 2012;1-8.

29. Acton RT, Barton JC, Barton JC. Serum ferritin, insulin resistance, and metabolic syndrome: clinical 
and laboratory associations in 769 non-hispanic whites without diabetes mellitus in the HEIRS study. Metab Syndr Relat Disord. 2015;13(2):57-63.

30. Huang J, Karnchanasorn R, Ou HY, Feng W, Chuang LM, Chiu KC, et al. Association of insulin resistance with serum ferritin and aminotransferases-iron hypothesis. World J Exp Med. 2015;5(4):232-43.

31. Yousouf R, Khan M, Kounsar Z, Ahanga S, Lone A W. Polycystic Ovarian Syndrome: Clinical Correlation with Biochemical Status. Surgical Sci. 2012;3:245-8.

32. Wen PC, Cheng TYD, Tsai SP, Chan HT, Hsu HL, Hsu CC, et al. Are Asians at greater mortality risks for being overweight than Caucasians? Redefining obesity for Asians. Public Health Nutrition. 2008; 12(4):497-506.

33. Ehrmann DA, Sturis J, Byrne MM, Karrison T, Rosenfield RL, Polonsky KS, et al. Insulin secretory defects in polycystic ovary syndrome. Relationship to insulin sensitivity and family history of non-insulin- dependent diabetes mellitus. J Clinical Investig. 1995;96(1):520-7.

34. Pedersen SD, Brar S, Faris P, Corenblum B. Polycystic ovary syndrome: validated questionnaire for use in diagnosis. Can Fam Physician. 2007;53(6):1042-7.

35. Faranak S, Sahar M, Nouraddin M. High Serum Ferritin Concentrations in Polycystic Ovary Syndrome Is Not Related to Insulin Resistance. Iranian J Diabet Obesity. 2011;3(2):47-53.

36. Jung CH, Lee MJ, Hwang JY, Jang JE, Leem J. Elevated Serum Ferritin Level Is Associated with the Incident Type 2 Diabetes in Healthy Korean Men: A 4 Year Longitudinal Study. PLoS ONE. 2013;8(9):75250.

Cite this article as: Begum T, Ishra S, Sharifa BS, Nahar S, Begum HA, Khan SS. Association of serum ferritin with insulin resistance in women with polycystic ovarian syndrome. Int J Reprod Contracept Obstet Gynecol 2021;10:2924-31. 